\title{
DE QUE LUGAR FALAMOS? Retomando um velho papo sobre o Direito e a Sociologia // Wanda Capeller ${ }^{1}$
}

\section{Palavras-chave:}

epistemologia / positivismo / ciência do direito / discurso jurídico / campo jurídico / Teoria Social

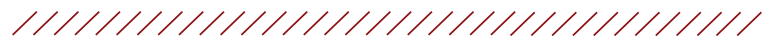

\section{Sumário:}

\section{Introdução}

2 Uma ironia epistemológica, o impacto da filosofia positivista no positivismo jurídico

2.1 O não reconhecimento dos direitos

2.2 A inversão das premissas do positivismo científico

2.3 Efeitos em série da ironia epistemológica

3 Os entendimentos do discurso jurídico

3.1 O discurso jurídico

3.2 A noção de campo jurídico

4 As tensões epistemológicas entre o direito e as teorias sociais

4.1 O direito presente nas teorias sociais clássicas

4.2 O direito presente nas teorias sociais atuais

5 Considerações finais

6 Referências

\section{Resumo}

Os juristas que pretendem realizar estudos sócio-jurídicos devem enfrentar as mutações e os desafios da sociedade globalizada. O ensino jurídico, destituído de uma visão sociológica, não fornece os instrumentos teóricos necessários para uma reflexão sobre o mundo social que ultrapasse as lógicas formais normativas. Este artigo denuncia essas dificuldades ao abordar as relações conflituais entre o Direito e a Sociologia do Direito, consequência da ironia epistemológica que constituiu a adoção pelos juristas do positivismo filosófico. Se as Ciências Sociais tendem a ignorar o Direito como elemento fundador das práticas sociais, diversos paradigmas sociológicos mobilizaram o Direito como um fio condutor para a explicação dos fatos e das mudanças sociais. De todos os modos, os pesquisadores desta área devem atentar para a questão da importação de modelos, utilizando de maneira crítica as teses produzidas pelas sociedades centrais.
1 Professora Catedrática de Sociologia do Direito, Institut des Sciences Politiques de Toulouse. Membro do Comitê de Redação da Revue Droit et Société, Paris. 


\section{WHICH PLACE ARE WE SPEAKING FROM? Returning to a long- standing talk about Law and Sociology // Wanda Capeller}

\section{Keywords}

epistemology / positivism / legal science / legal discourse / legal field / Social Theory

HIIIIIIIIIIIIIIIIIIIIIIIIIIIIIIIIII

\begin{abstract}
Legal scholars that seek to perform social legal studies have to face the challenges and transformations of a globalized society. Legal education without a sociological perspective will not provide the theoretical tools to understand the complexities of the social world that go beyond the normative and formal logic. This article reveals the difficulties to tackle the conflictual relationship between Law and Sociology of Law, which is a consequence of the epistemological irony of the adoption of philosophical positivism by legal scholars. If Social Science tends to ignore Law as a founding element of social practices, many sociological paradigms mobilized Law as common thread to explain social facts and changes. In any case, researchers in this area should be aware of the issue of importing models, using the thesis produced in this way in a critical manner.
\end{abstract}




\section{Introdução}

$\mathrm{Na}$ era de globalização neoliberal, os juristas estão tendo que afrontar as intensas mutações do direito e seus efeitos perversos no campo social. Com efeito, o direito moderno, portador de seguranças, certezas e garantias individuais, foi dando lugar a um direito pós-moderno, pragmático, multirracional, pluralista, fragmentado e complexo (Arnaud, 2004), sistêmico (Luhmann, 2004), 'soft' (Wroblewski, 1986; Delmas-Marty, 1986 e 1998; Arnaud \& Fariñas Dulce, 1998, p. 323 e ss.), cujas lógicas atendem às demandas dos sistemas financeiros e do mercado global de consumo (Bauman, 2013). Este direito estratégico, funcional e instrumental, que não passa necessariamente por um processo de legtitimação discutido no 'mundo da vida' (Habermas, 1981; Melkevik, 1992, p.127), sacrifica a proteção dos indivíduos na área dos direitos sociais, e adquire as formas de um 〈direito líquido〉 que, por exemplo, na área do direito do trabalho, gera um 'direito de exceção' permanente (Ferreira, 2012, p.75 e ss.), e no âmbito da governança global apresenta uma regulação de 'texturas abertas', imposta notadamente pelas agências globais (Arnaud, 2014).

Nesses contextos fluídos do direito, os juristas encontram ainda maiores dificuldades quando pretendem realizar pesquisas empíricas de cunho sociológico, uma vez que, neste campo, devem enfrentar também questões de ordem epistemológica e metodológica inerentes ao próprio estatuto científico da sociologia do direito. Disciplina bicéfala, onde a sociologia e o direito encaram-se "comme des chiens de faïence" com olhos mutualmente suspiciosos, ou cdisciplina Janus) (Commaille \& Perrin, 1985), de uma só cabeça e duas faces opostas, a sociologia do direito apresenta muitas dificuldades epistemológicas. A isso soma-se o fato de que os pesquisadores oriundos do direito não possuem em geral os alicerces teóricos $\mathrm{e}$ técnicos das ciências sociais para desenvolver o trabalho sócio-empírico. Se o aprendizado dos juristas-sociólogos faz-se pela apreensão das lógicas do normativismo formalista das "ciências jurídicas" e do dogmatismo positivista, como abordar o campo interdisciplinar e alargado dos estudos sócio-jurídicos (Arnaud, 1992) sem ter que abandonar o direito?

Para Jean Carbonnier, a sociologia do direito consti- tui uma disciplina "à part entière", que delimita um território disciplinar próprio destinado a estudar as normas jurídicas e as regras institucionais que regem os comportamentos dos atores sociais. Para analisar categorias jurídicas específicas, essa disciplina empresta da sociologia os conceitos e os métodos, e serve-se das técnicas de pesquisa das ciências sociais (Carbonnier, 1972). Mas o fato é que o direito durante muito tempo considerou as ciências sociais como 'ciências auxiliares', simples 'servidoras' do direito (Arnaud, 1997). Sobre isso, o exemplo da criminologia na França é emblemático: os juristas a utilizam como um 'saber auxiliar' do direito penal, e os cientistas sociais a consideram um 'saber da repressão' e da dominação social, ambos procurando impedir sua institucionalização como disciplina justamente num país onde a territorialização das disciplinas é fundamental para a determinação das carreiras profissionais. Ora, se o direito 'coloniza' as ciências sociais, essas também o 'colonizam', e servem-se dele mais das vezes como uma variável periférica.

Afinal, de que lugar falamos? A 'partir do direito', 'sobre o direito', 'contra o direito'? A dualidade explícita da expressão "direito e sociedade" (law and society, droit et société), ou implícita do termo posteriormente usado "direito na sociedade" (law in society), não resolve a questão dicotômica da sociologia do direito, dividida entre uma visão relativamente autônoma do direito e uma visão autoconstruída (sem direito?) do mundo social. Preocupados com essas questões, François Ost e Michel van de Kerchove sugeriram uma abordagem complementar, suscetível de englobar o 'direito interno' e o 'direito externo' numa 'perspectiva interna/ externa' do direito (Ost \& Van de Kerchove, 1988). O debate, todavia, persiste, notadamente quando juristas e cientistas sociais afrontam seus pontos de vista. Foi por esta razão que o Comitê de Redação da Revue Droit et Société decidiu publicar dois volumes numa espécie de 'jogo de espelhos' para dar a palavra a ambos os tipos de pesquisadores. ${ }^{2}$

Pergunta-se todavia: como o direito pode ser mar-

2 Ver Ed. Juridiques Associées. (2008). Dossier Quelles méthodes pour la sociologie du droit et de la justice? Revue Droit et Société, (69-70), e Ed. Juridiques Associées. (2010). Dossier Sciences sociales, droit et science du droit: le regard des juristes, Revue Droit et Société (75). 
ginalizado pelos cientistas sociais em trabalhos que pretendem examinar o fenômeno jurídico? Como ofuscar o impacto das transformações das racionalidades jurídicas no mundo social? Arnaud (2004), ao analisar o direito na transição da modernidade à pós-modernidade, mostrou que as racionalidades jurídicas que surgiram neste momento fundaram novas lógicas normativas globais. Também, Ferreira observou as novas racionalidades do direito do trabalho que servem de justificativa ideológica às políticas de austeridade impostas pelo neoliberalismo na Europa. Segundo ele, o desmantelamento do direito do trabalho não somente determina novas formas de regulação jurídica, mas também novas formas de regulação política, legitimando o poder dos não eleitos, dos agentes globais (Ferreira, 2012; 2014).

Para aprofundar essas questões, proponho uma reflexão em três tempos: (i) uma ironia epistemológica, o impacto da filosofia positivista no positivismo jurídico, (ii) os entendimentos do discurso jurídico, e (iii) as tensões epistemológicas entre o direito e as teorias sociais.

\section{Uma ironia epistemológica, o impacto da filosofia positivista no positivismo jurídico}

No início do século XIX, o positivismo de Auguste Comte procurou dar respostas às mutações e crises sociais provocadas pela afirmação da sociedade industrial nos países ocidentais, onde surgiam conflitos entre o capital e o trabalho, antagonismos sociais, uma grande concentração urbana e novas formas de organização das classes trabalhadoras, consideradas como 'classes perigosas' (Chevalier, 1958). Nessa época de temor do socialismo, foram bem aceitas as ideias de Comte que preconizavam um Estado forte, centralizador, capaz de estabelecer a ordem para chegar ao progresso. Por curiosidade, lembramos que o termo sociologia - proposto por Comte (1839), que inicialmente havia pensado no termo 'física social' (já antes utilizado por Adolphe Quételet para nomear a estatística) -, aparece ao mesmo tempo que os termos 'socialista' (pronunciado pela primeira vez em 1835, na Inglaterra, pelo deputado C. Owen) e 'socialismo', que data de 1841. A sociologia ficou, desde logo, marcada de conotação política.
Consagrado à missão de reformadora, o positivismo filosófico comtiano se situou na antítese dos autores antimarxistas que desejavam um retorno à História, mas também dos autores socialistas que queriam mudar a sociedade pela ação política (Comte, 1822). Ao rejeitar as crenças metafísicas, teológicas e socialistas, e combinando as noções de Ordem e Progresso, o positivismo pretendeu criar uma Nova Ordem Social ao difundir sua doutrina política, muito útil, aliás, às elites latino-americanas que buscavam reforçar e modernizar o Estado sem mudanças bruscas, destruição das instituições ou revolução social. As elites militares brasileiras do fim do século XIX, por exemplo, adotaram sem reservas a doutrina positivista como base teórica e ideológica para a República, proclamada em 1889. A Primeira República, de fato, fundada na doutrina de um Estado forte e centralizador, tornou-se rapidamente a primeira ditadura militar brasileira.

Do ponto de vista científico, o positivismo filosófico baseou-se em dois princípios: a observação dos fatos e a enunciação de leis fundadas na observação empírica das regularidades sociais. A doutrina comtiana centra-se na noção de unidade: unidade da História, unidade humana, unidade social. Para Comte, o homem é o mesmo em todos os lugares e em todos os tempos, visão que determinou uma mentalidade etnocêntrica na Europa, que, com base nesse etnocentrismo cultural, justificou os processos de colonização de povos tidos como 'atrasados' em relação à sociedade superior positiva, quer dizer a sociedade industrial moderna dominada pela ciência e tecnologia. Assim, a ciência ocidental passa a ser a ciência de toda a humanidade, apontando para um modelo de sociedade para o qual deveriam convergir todos os povos (Aron, 1967, p.79 e 86). No final do século XIX, de fato, a economia-mundo capitalista expandiu-se à totalidade do planeta, e nessa época, pela primeira vez na história da humanidade, chegou-se a um sistema histórico único, o 'sistema-mundo' (Wallerstein, 1980).

Nesse quadro teórico, o direito saiu perdendo, essencialmente por duas razões: a primeira porque o positivismo filosófico não reconheceu direitos subjetivos e individuais; a segunda porque o impacto do positivismo filosófico no positivismo jurídico resultou de uma inversão das próprias premissas do positivismo científico. 


\subsection{O não reconhecimento dos direitos}

Em termos filosóficos, o positivismo significou uma regressão em relação às ideias do lluminismo, que outorgara direitos individuais inalienáveis. Se Montesquieu percebeu toda a diversidade humana e social, o seu pluralismo, o pluralismo jurídico, e conseguiu dificilmente encontrar uma certa ordem no caos aparente, Comte, por sua vez, não reconheceu a diversidade humana e social (Aron, 1967, p.79) nem direitos subjetivos e individuais. Na sua obra Catéchisme positiviste, ele questiona o direito, seus fundamentos, seu sentido e seu valor. Na sua visão holista, a sociedade é composta de organismos sociais, de 'famílias' e não de indivíduos, pois domina o principio segundo o qual o 'todo é superior às partes' (Comte, 1852).

Comte chega, assim, ao objetivo último de toda filosofia anti-histórica, ou seja, ao mito da sociedade sem direito. Para ele, o indivíduo, ser social, deve ser colocado face às suas responsabilidades sociais, dado que é um ser fundamentalmente social. A ideia de direito é, portanto, absurda e imoral, pois supõe que o homem constitua uma individualidade absoluta. Os indivíduos não têm direitos, somente deveres. A posição antijurídica de Comte é resultante de sua oposição ao jusnaturalismo jurídico, que considerou como traços da metafísica. Por isso critica de maneira virulenta a noção abstrata e subjetiva do direito, distanciada do mundo social. Portanto, uma mentalidade positivista se difundiu na cultura europeia, dominando-a por muito tempo, e a doutrina positivista foi adotada por todas as teorias que rejeitavam a metafísica (Fasso, 1974, p.122).

\subsection{A inversão das premissas do positivismo científico}

Se a expressão 'positivismo jurídico' só apareceu no final do século XIX, os juristas dessa época já se consideravam positivistas por terem aderido ao 'direito positivo' que rejeitava o direito natural. 0 próprio termo 'positivismo jurídico', que vincula o direito ao positivismo filosófico, parece ser um contrassenso na medida em que este último é indiferente ao direito. Seguindo a orientação de Comte, que afirmava ser a construção científica essencial para qualquer tipo de conhecimento, os juristas quiseram construir uma 'ciência do direito', o que caracteriza uma verdadeira ironia epistemológica. Portanto, no momento do triunfo do positivismo filosófico contra a religião, a metafísica e outras filosofias transcendentais, o sonho dos juristas parecia ser perfeitamente viável, não fosse o paradoxo das consequências. Com efeito, ao propor o método formalista, o positivismo jurídico situou-se numa perspectiva diametralmente oposta ao positivismo filosófico (Fasso, 1974, p.138). A ciência do direito foi elaborada como uma teoria das normas baseada num sistema normativo racional, afastando assim os juristas da sociologia do direito tida como uma ciência aproximativa. De fato, o projeto científico dos juristas formou-se a partir do desejo de igualar o direito e as ciências exatas em relação às quais sempre sentiram um complexo de inferioridade (Fasso, 1974, p.139).

Mas, afinal, existe uma epistemologia jurídica? Christian Atias afirma que os juristas falam em ciência do direito sem nenhuma pretensão epistemológica, e que se há uma 'epistemologia jurídica', ela constitui uma 'epistemologia jurídica descritiva', na qual o objeto não é o direito, mas o conhecimento do direito. A epistemologia jurídica descritiva serve a "compreender o que os juristas procuram conhecer, apreciar os meios que eles empregam e determinar qual pode ser a influência destes procedimentos de conhecimento do Direito sobre o direito que é o objeto". Por conseguinte, os juristas devem responder a uma só questão: como se pode reconhecer e interpretar o direito? Ou seja, a ciência do direito não procura compreender e explicar a conduta humana senão como objeto ela mesma de normas jurídicas (Atias, 1985, p.16 e ss.).

Nesse sentido, Bourdieu afirma que a teoria do direito de Hans Kelsen correspondeu à 'ultra-consequência' do esforço dos juristas para criar um corpo de doutrinas e regras que achava em si mesmo seu próprio fundamento, independentemente de todas as pressões sociais (Bourdieu, 1986). Autor neokantiano, Kelsen inspirou-se na Teoria da Razão Pura de Kant e em sua filosofia transcendental, que se opunha à metafísica, para elaborar sua obra a Teoria Pura do Direito (Kelsen, 1934). A teoria kelsiana é contrária ao direito natural que possui caráter universal e que corresponde à metafísica no âmbito jurídico e social (Kelsen, carta à Renato Treves de 3 de agosto de 1933).

Sem querer adentrar debates próprios à teoria do direito, vale lembrar que a perspectiva epistemológi- 
ca da ciência das normas de Kelsen levou-o à noção de Grundnorm, de norma fundamental, que é preciso 'supor' para poder 'instaurar' uma ordem jurídica. Nesta 'hipótese lógico-transcendental'3 refletiu-se a inspiração kantiana de Kelsen, que, ao questionar o modo de produção das normas jurídicas, necessário para descrever cientificamente a estrutura e a dinâmica da pirâmide jurídica, não pode eludir o problema do fundamento da validade das ordens normativas. Sobre este ponto, Simone Goyard-Fabre aponta para um aspecto desconcertante: ela explica que não se deve confundir a Constituição - que é o cume da pirâmide do direito positivo -, com a Grundnorm, que é uma 'norma básica' que não pertence ao direito positivo, mas apenas torna-o possível e pensável enquanto direito válido (Goyard-Fabre, 1994, p.228).

Ainda desconcertante é a afirmação de Kelsen, segundo a qual a teoria pura do direito, inspirada na 'teoria da experiência' de Kant, é uma teoria 'empírica'. Se o direito positivo pode ser entendido como 'direito na experiência' ou 'experiência jurídica', ele é necessariamente direito empírico, e a teoria pura do direito é certamente empírica (carta a Renato Treves, 1933). Ao meu ver, esta afirmativa pode confundir os que pretendem fazer uma 'sociologia jurídica dos juristas' (Arnaud \& Fariñas Dulce, 1998, p. 103 e ss.), pois o 'positivismo singular' de Kelsen, ao defender a tese da normatividade pura, estabelece uma clara distinção conceitual entre direito e fato social, contrariamente ao positivismo jurídico tradicional que afirma a inseparabilidade do direito e do fato (Paulson, 1997, p. 4).

O positivismo jurídico exige uma lógica formal que abstrai todos os conteúdos, sejam eles valores éticos, realidades histórico-sociais ou empíricas. Há, portanto, na teoria do direito de Kelsen uma exigência total

3 Segundo a Crítica da Razão Pura de Kant, todo conhecimento que gera, não objetos, mas conceitos a priori como objetos, é transcendental. Na teoria do conhecimento de Kant, a filosofia transcendental ou idealismo transcendental teve como objetivo justificar a possibilidade do conhecimento científico do século XVIII. Ela partiu da constatação de que nem o empirismo inglês, nem o racionalismo continental, explicavam satisfatoriamente a Ciência. Kant mostrou que, apesar de o conhecimento se fundamentar na experiência, essa nunca se dá de maneira neutra, pois a ela são impostas as formas a priori da sensibilidade e do entendimento, características da cognição humana (Silveira, 2002). de pureza, e as normas jurídicas são vistas somente enquanto normas, eliminando-se do conceito de 'ciência jurídica normativa' toda consideração moral, psicológica, histórica e sociológica. Na verdade, os próprios juristas criticaram essa 'ciência do direito' de um normativismo exclusivo e excludente. Pashukanis (1988, p.47) afirma que o direito, enquanto conjunto de normas, é apenas uma 'abstração sem vida', e que a escola normativa negou a relação entre os sujeitos, desconsiderando o direito sob o ângulo da sua existência real ao centrar sua análise no valor formal das normas. Mais recentemente, Ricci afirma indispensável evidenciar a natureza das relações entre 'enunciados prescritivos' e 'enunciados da existência' (Ricci, 2002), e Paul Amselek (1994), no seu livro Méthode phénoménologique et Théorie du Droit, considera a teoria pura do direito como uma das primeiras manifestações da fenomenologia do direito (Amselek, 1994; Kalinowski, 1969; Perrin, 1993; Guerra Filho, 2008).

Se o formalismo jurídico teve raízes no jusnaturalismo, ele não esperou o positivismo para afirmar-se como paradigma: o conceptualismo e o formalismo da dogmática jurídica encontraram sua máxima expressão na elaboração das teorias gerais do direito do final do século XIX e meados do século XX. Mas o positivismo jurídico, fundado no cientifismo positivista, vai mais longe ao construir um formalismo normativista puro, que significou a negação do positivismo filosófico. Este último pretendia descobrir as leis e as regularidades racionalmente formuláveis dos fatos reais, e não as relações entre conceitos não referentes a realidades concretas (Fasso, 1974, p. 146). Portanto, a concepção kelseniana do direito positivo formal, dogmático e empírico confunde o jurista quando de sua intenção de fazer pesquisa sócio-empírica.

\subsection{Efeitos em série da ironia epistemológica}

Tal concepção do direito provoca efeitos perversos em série: o primeiro efeito perverso diz respeito ao próprio ensino do direito, concebido como um monismo estatal oficial que limita as fontes do direito às fontes normativas oficiais, e erradica de sua conceptualização a cultura e as interações intersubjetivas dos sujeitos sociais. Ora, sabemos que a pesquisa em direito não se limita ao estudo das normas jurídicas positivadas pelo direito estatal, nem tampouco ao estudo das ins- 
tituições jurídicas, pois a resolução de conflitos passa igualmente pela esfera dos direitos alternativos.

O segundo efeito perverso resulta do primeiro, pois se refere à cristalização dos conhecimentos e dos conceitos jurídicos. A transmissão e a petrificação da ciência positivista do direito nas faculdades de direito, limitando-se em geral a um aprendizado das normas, de sua exegese e de suas tecnologias procedurais, encerram os juristas num debate interno, normativo lógico-formal e dogmático (Fasso, 1974). Em muitos países o ensino do direito exclui elementos históricos, psicológicos e sociais e as referências às funções sociais que asseguram a implementação das normas jurídicas (Bourdieu, 1986). Na França, recentemente, em artigo dedicado ao ensino do direito no século XXI, afirmou-se que "é preciso não acreditar que a formação jurídica pode favoravelmente ser diluída nas ondas pluridisciplinares" (Lasserre, 2013, p. 24). Daí que os estudantes de direito assumem, sem questionar criticamente, uma alienação técnica, tornando-se indiferentes à compreensão do direito como expressão de experiências jurídicas objetivas, intersubjetivas e incorporadas pelos indivíduos. Como profissionais, mais tarde, estarão destinados a exercer em espaços jurídicos fechados e autorreferenciais, onde os juristas práticos (advogados, juízes, etc.) recorrem às normas e ao discurso jurídico como uma 'arte de persuasão'.

O terceiro efeito perverso é consequência do segundo, pois trata do postulado kelseniano da autolimitação da pesquisa ao enunciado das normas jurídicas. $\mathrm{Pa}$ rece ser que, nos meios jurídicos, dá-se menos importância ao trabalho científico, dado que os profissionais dessa área ostentam com orgulho a etiqueta de operadores jurídicos (Guerra Filho, 2008). De fato, os operadores do direito utilizam uma linguagem-objeto e se comunicam entre si por meio das formas específicas do discurso jurídico.

\section{Os entendimentos do discurso jurídico}

Não posso resistir de trazer aqui a deliciosa passagem do livro A Tragédia da Rua das Flores de Eça de Queiroz (1982, pp. 193-195):

Mas o procurador Gurjão entrou... E vindo sentar- -se subitamente ao pé de Vitor, disse-lhe, olhando- o por cima da luneta, com brandura:

- Se uma inscrição de hipotéca, procedente ao mesmo título, tiver sido tomada em diversas conservatórias, e a acção se houver de intentar "no julgado onde estiver situada a maior parte dos bens onerados", será onde esses bens pagarem mais contribuição directa, ou no julgado do domicilio do registrante? Hem?

Vitor olhou-o com terror. Não tinha percebido absolutamente nada da idéia do Gurjão. Fez-se repetir o caso. Torcia o bigode, com os olhos esgazeados.

- Vossa Excelência não se recorda? E consultando uma nota: Código, capítulo $10^{\circ}$, secção $4^{\circ}$, subsecção $7^{\circ}$, divisão $5^{\circ}$. Deve ser por ai...

Vitor bateu a porta... Desceu a escada. Na rua respirou amplamente. Estava resolvido a não voltar ao escritório.

Essas linhas do grande Eça mostram bem que a linguagem jurídica - que é a linguagem da norma jurídica (Rechtsnorm), e que emprega amiúde a forma verbal deve, forma o vocabulário de uma linguagem-objeto, que é precisamente a linguagem das normas (Kalinowski, 1969, p. 88). Essa linguagem-objeto afasta os juristas das possibilidades de comunicação fora do 'huis-clos' do direito, e os impede de exercer a 'dupla hermenêutica' (Giddens, 1987, p. 392) para reabilitar o senso comum, cuja dimensão utópica e libertadora amplia os conhecimentos. Santos já havia alertado para o fato de que a ciência moderna "se faz do cientista um ignorante especializado, faz do cidadão comum um ignorante generalizado" (Sousa Santos, 1986, p. 25). Nos meios jurídicos pode-se dizer que o 'cientista ignorante' ou o 'ignorante generalizado', aprendem, ambos, rapidamente as formas banalizadas do discurso jurídico, escrito ou oral.

\subsection{O discurso jurídico}

O discurso jurídico pode ser abordado por diversos prismas, segundo a matriz epistemológica. Do ponto de vista sistêmico luhmanniano, o discurso jurídico permite, ao mobilizar seus próprios critérios normativos, a readaptação dos subsistemas de direito, que 
apesar de 'fechados', recebem informações através das aberturas cognitivas. As recursividades transformacionais realizadas com base nesses critérios caracterizam a autopoiese jurídica (Arnaud \& Fariñas Dulce, 1998, pp. 258-259). Na visão de Habermas, a legitimação do direito dá-se no 'mundo da vida', e passa por um processo específico de legitimação do discurso jurídico. Nessa abordagem, o que está em jogo é a validade social da construção de um 'mundo do agir regulado pelas normas', onde o papel do discurso jurídico consiste precisamente em edificar e transformar esse mundo regulado pelas normas. Os discursos sociais, no entanto, podem validar ou não as normas jurídicas, tornando-as controversas nos espaços das interações entre os sujeitos sociais. 0 discurso representa, então, uma forma de reciprocidade metacomunicacional, onde a validade das normas resulta de uma comunicação recíproca-reflexiva (Melkevik, 1992, pp. 127-128).

Para perceber o discurso jurídico como a 'forma por excelência de um discurso que age', como uma 'força da forma' (Bourdieu, 1986, p. 13 e ss.), temos que examinar a sociologia do direito de Pierre Bourdieu, plena de particularidades. Com efeito, esse autor não deu coerência aos seus trabalhos sobre o direito, reunindo-os de maneira esparsa em diversas publicações, em que se nota uma visão descontínua e fragmentada do direito na medida em que esse objeto foi vinculado a outros temas de sua sociologia. Bourdieu, de fato, não dissociou a teoria sociológica do direito de sua 'sociologia dos campos' (Bourdieu, Champagne \& Wacquant, 2013), concebendo o direito como um 'campo social' (Guibentif 2010, p. 272 e ss.). O seu texto La force du droit, referência maior da sociologia do direito, examina temas relevantes tais como o discurso jurídico, a divisão do trabalho jurídico, as relações entre juristas e não juristas, etc. Nele, o autor mostra que o monopólio dos juristas é resultante da incapacidade dos não-juristas, quando a situação o exige, de tratar juridicamente questões que necessitam uma redefinição normativa da experiência ordinária (Guibentif, 2010, p. 283)

Na sociologia bourdieusiana, o discurso jurídico e as práticas jurídicas são resultantes do próprio modo de funcionamento do campo do direito, cujas lógicas são duplamente determinadas pelas relações de forças específicas que conferem ao direito sua estrutura, e pelas obras jurídicas que formam o universo das soluções jurídicas. Assim elaborado, o discurso jurídico veicula a concepção do direito como uma 'ciência pura', que pode ser comparada com a linguística de Saussure que também constituiu uma 'teoria pura da língua'. Ao distinguir a linguística interna da linguística externa, Saussure excluiu igualmente toda referência às condições históricas, geográficas e sociológicas do funcionamento da língua e de suas transformações (Bourdieu, 1986, p.3-4).

Quanto à linguagem jurídica propriamente dita (que combina elementos da língua comum com elementos estrangeiros a ela, caracterizando a retórica da neutralidade e da impessoalidade), dela resultam vários efeitos: o efeito do apriorismo - afirmação anterior à experiência -, o efeito da neutralidade e o efeito da universalidade. Essa retórica da autonomia, da neutralidade e da universalidade estrutura a relativa autonomia do campo jurídico, de seus princípios e práticas, o que determina o 'espírito jurídico' e o ‘senso jurídico'. O 〈espírito jurídico〉 é uma 〈postura universalizantes que autoriza uma forma específica de julgamento, irredutível às intuições inconstantes do sentido de equidade (Bourdieu, 1986, p. 3 e ss.; Guibentif, 2010, p. 282). Ora, essa abstração constitutiva do direito ignora a prudência prática da equidade (Bourdieu, 1986; Guibentif, 2010), de modo que as práticas jurídicas se caracterizam como 'força da forma': "como a prática religiosa, a prática jurídica se define na relação entre o campo jurídico, princípio da oferta jurídica que se forma na concorrência entre os profissionais, e as demandas dos profanos que são sempre em parte determinadas pelo efeito da oferta" (Bourdieu, 1986, p. 14).

Por muito tempo o debate científico sobre o direito situou-se na dualidade formalismo vs. instrumentalismo: o formalismo afirmando a autonomia absoluta da forma jurídica em relação ao mundo social, e o instrumentalismo que concebe o direito como um reflexo ou um instrumento a serviço dos dominantes. A ideia do direito como instrumento do poder, de raízes neomarxista, alcançou grande repercussão na América Latina, notadamente no Brasil, não somente em razão da época ditatorial do continente, mas também pela difusão do movimento Critique du droit 
(Saffon \& Villegas, 2011, pp. 149-172). Diga-se de passagem que esse movimento crítico do direito, apesar de sua riqueza teórica, ocupou um espaço marginal nos meios intelectuais, políticos e jurídicos franceses (Kaluszynski, 2011, p. 34). Por sua vez, a sociologia bourdieusiana também abandonou a visão marxista do direito porque esta ignorou a estrutura dos sistemas simbólicos (Bourdieu, 1986, p. 3), e ao mesmo tempo refutou a percepção binária internalista ou externalista do direito que não considera a existência de um universo social relativamente independente das demandas externas, mas no interior do qual se produz e exerce a autoridade jurídica, forma por excelência da violência simbólica legítima de monopólio do Estado. Para romper com esses impasses teóricos, Bourdieu (1986, p. 4) aplica ao direito sua noção de ‘campo': o ‘campo jurídico' é um espaço social que se caracteriza como o 'lugar' da concorrência pelo monopólio do direito de 'dizer-o-direito'.

\subsection{A noção de campo jurídico}

Sobre o 'campo jurídico' cabem, ao menos, quatro observações: a primeira diz respeito ao fato de que, na sociologia do direito francesa, a noção de campo jurídico foi inicialmente trabalhada por André-Jean Arnaud no livro Critique de la raison juridique. Où va la sociologie du droit, publicado em 1981. Mais tarde, no decorrer dessa década, Bourdieu realizou no Collège de France um Seminário dedicado ao tema do 'campo jurídico', a partir do qual publicou posteriormente os textos La force du droit e La codification, em 1986 (Guibentif, 2010, p. 274). Mesmo se Bourdieu refere-se ao trabalho de André-Jean Arnaud, este último não se havia inspirado da teoria bourdieusiana dos campos para elaborar suas teses, mas sim da teoria das formas matemáticas das análises estruturais (testemunho oral à autora). Portanto, as duas noções de 'campo jurídico' apresentam semelhanças. Para Arnaud, o campo do direito é delimitado por uma zona espacial onde forças de natureza antagônicas e concorrentes se confrontam, nos espaços do 'campo jurídico vulgar' do ‘antes-do-dizer-do-direito', para 'dizer-o-direito' (Arnaud, 1981, p. 324 e ss.). Para Bourdieu, a teoria dos campos centra-se na análise dos interesses e das práticas dos agentes sociais que lutam no mesmo entorno social (campo), estabelecendo estratégias, no caso campo jurídico, para 'dizer-o-direito'.
A segunda observação refere-se à diferença, indicada pelo próprio Bourdieu, entre as noções de 'campo jurídico' e 'sistema jurídico'. Para esse autor, a teoria luhmanniana da autorreferência das estruturas legais confunde as estruturas simbólicas - o direito propriamente dito - com as instituições sociais das quais elas resultam. Segundo ele, Luhmann ressuscita a ideia do sistema jurídico que se transforma segundo suas próprias leis, notadamente porque não estabelece a distinção entre 〈registro simbólico〉 das normas e das doutrinas e <registro das relações objetivas` dos agentes e das instituições. Por essa razão, a teoria luhmanniana continua fornecendo aos juristas um quadro ideal da representação formal e abstrata do sistema jurídico (Bourdieu, 1986, p. 4).

A terceira observação aponta para o amálgama que faz Bourdieu, no seu texto La force du droit, entre 'campo jurídico' e 'campo judiciário', expressões que utiliza de maneira alternativa. Sobre esse ponto, Pierre Guibentif sugere que o termo 'campo jurídico' seja usado quando se trata das instâncias onde se reúnem os juristas que se identificam reciprocamente como tais, sem a presença dos não juristas. Outros conceitos poderão ser criados para referir-se às instâncias onde juristas e não juristas interagem, como, por exemplo, os conselhos de peritos, os debates mediáticos ou digitais (Guibentif, 2010, p. 284).

A quarta observação trata da evolução da noção de 'campo jurídico', cuja concepção tornou-se bastante mais fluida, nas palavras de Yves Dezalay, que no seu texto Les usages internationaux du concept de champ juridique mostra como, no curso Sur l'État, realizado no Collège de France nos anos 1989-1992, Bourdieu, apoiando-se nos trabalhos dos historiadores, opõe várias categorias de juristas, segundo suas origens sociais, sua formação e sua proximidade com o poder. Essas análises deram lugar a uma visão dos campos jurídicos como espaços de múltiplas dimensões, onde as relações se transformam, e onde os detentores do capital jurídico agem segundo suas estratégias e posições ideológicas em função do contexto histórico e político (Dezalay, 2013, p. 58).

Esses diversos entendimentos do direito e do discurso jurídico evidenciam a existência de várias tensões, notadamente tensões epistemológicas entre o direi- 
to e as teorias sociais. É o que veremos no terceiro tempo de nossa argumentação.

\section{As tensões epistemológicas entre 0 direito e as teorias sociais}

As tensões epistemológicas do direito contribuíram para eliminá-lo do campo social, e sua natureza normativa o excluiu das teorias descritivas e explicativas das ciências sociais. Weber distinguiu metodologicamente a dogmática jurídica e a sociologia do direito, apontando para possibilidades de complementaridade prática entre as duas abordagens do direito. Segundo ele, o jurista quer saber qual é a significação do 'sentido normativo' atribuído a uma certa construção da linguagem dada como norma jurídica, e o sociólogo, por sua vez, leva em conta, do ponto de vista subjetivo, as prescrições pelas quais os atores sociais orientam suas atividades. Desse modo, a abordagem dogmático-jurídica tem como finalidade estabelecer a coerência entre as proposições jurídicas, organizando-as num sistema lógico isento de contradições, e a abordagem sociológica busca saber qual é o comportamento dos membros de um grupo em relação à ordem jurídica em vigor.

Historicamente, a sociologia do direito inspirou-se na sociologia nascente, e se construiu em reação à dogmática jurídica, procurando situar-se em relação aos saberes jurídicos que lhe eram próximos, como a filosofia do direito e a teoria do direito, e igualmente em relação às demais ciências sociais. Percebida como uma disciplina 'carrefour' (Arnaud, 1988), um 'ponto de encontro' entre vários saberes, seus esforços foram inúteis para minimizar as desconfianças existentes entre o direito, a sociologia e demais ciências sociais. Os juristas veem a sociologia como uma 'empresa de subversão', e os sociólogos veem o direito como um instrumento do poder, como um veículo da dominação social (Commaille, 1991, p. 13). Por isso a sociologia do direito procura identificar de que maneira o campo jurídico posiciona-se em relação ao campo do poder (Bourdieu, 1986, p. 6), e desvendar as ligações, às vezes perigosas, entre o direito, o poder e o Estado (Capeller, 1992; 1995). Essas perspectivas têm inspirado recentemente alguns sociólogos franceses do direito que desenvolvem uma sociologia política do direito (Commaille, 1994; Commaille, Dumoulin, \&
Robert, 2000), ou ainda o conceito de governança que aplicado a diferentes práticas pode suplantar o poder dos governantes (Arnaud, 2014, cap. 4).

Se o direito, a sociologia e as demais ciências sociais sentem-se constantemente ameaçados, uns pelos outros, de desqualificação e instrumentalização, isso se deve às incompreensões e à falta de consciência, por parte das ciências sociais não jurídicas, da importância do jurídico como objeto de estudo. Por outro lado, a ausência de uma formação específica para os juristas, faz com que seus estudos empíricos sofram de um déficit teórico. Para além, a descaracterização da sociologia jurídica como um saber específico e a disseminação da pesquisa jurídica entre diversas comunidades disciplinares podem provocar ressentimentos mútuos.

Os cientistas sociais, no entanto, começam a perceber que não podem fugir a priori dos aspectos da construção lógico-formal do direito, mesmo se privilegiam as análises a posteriori da construção social do direito por meio do estudo das atividades institucionais e organizacionais, e da ação dos atores sociais (Commaille, 2014). Eles reconhecem igualmente que os atores jurídicos estabelecem estratégias de concorrência, internas e externas ao campo jurídico, afirmando posições sociais de saber e de poder (Bourdieu, 1986). Casimiro Ferreira insiste, então, para que a sociologia preste mais atenção às normas e às regras, sem o que não poderá abordar conceitos como 'ação', 'legitimidade', 'normas' e 'valores'. Segundo ele, apesar da importância da sociologia do direito para a sociologia, o pensamento e a pesquisa sociológica não têm mostrado interesse por conceitos e problemáticas fundamentais como, por exemplo, a dos direitos humanos (Ferreira, 2014, pp. 313-314).

Pode o direito ser incluído nas epistemologias das ciências sociais? Em outro lugar, tive a oportunidade de debater com o epistemólogo francês Jean-Michel Berthelot, que no seu livro Epistémologies des Sciences sociales havia descartado deliberadamente os conhecimentos jurídicos do espaço epistêmico das ciências do social. Para ele, as ciências do direito fundamentam julgamentos normativos, nada tendo a ver com as ciências sociais que buscam explicar os 
fatores que determinam esses universos normativos, e querem compreender as razões pelas quais a ele aderem os atores sociais (Berthelot, 2001, p. 12; Capeller, 2003, pp. 215-228). Ora, o direito sempre esteve presente na teoria sociológica mesmo se a ligação entre a sociologia geral e este fenômeno sociológico não é evidente. Assim, as referências ao direito como fato social ou como indicador de padrões de solidariedade social fazem parte do processo de teorização sociológica, mesmo se há uma dissociação entre a reflexão sócio-jurídica e a 'imaginação sociológica'. Existe, pois, um paradoxo na história do pensamento na medida em que o direito, cuja a importância foi assumida pelo pensamento sociológico clássico, desaparece dos debates sociológicos nos anos 19601970, momentos, portanto, de viragens determinantes para a reestruturação da sociologia contemporânea (Ferreira, 2014, p. 313).

\subsection{O direito presente nas teorias sociais clássicas}

Observamos em diversos paradigmas das teorias sociais a presença do direito como fator explicativo maior. Segundo François Chazel, o programa de pesquisa em direito da escola durkheimiana - que se formou contra a tentação de relegar o direito aos aspectos metafísicos como havia feito Auguste Comte, enriqueceu a sociologia geral e estabeleceu as bases de uma nova área de saber, a sociologia do direito (Chazel, 2000, p. 182; Didry, 2011). A sociologia do direito durkheimiana deve ser apreciada como uma reflexão sobre o direito dentro dos quadros do pensamento sociológico do fim do século XIX, notadamente das análises da ruptura e transição entre tradição e modernidade. Mas não é sob o ponto de vista metodológico que devemos apreciar a contribuição dessa escola, uma vez que o direito aí foi visto como um fato social excepcional comparável à religião, ficando fora do alcance dos métodos causais preconizados por Durkheim nas Regras dos Métodos Sociológicos (Didry, 2011). Para os durkheimianos, o direito é um símbolo, a expressão de uma realidade social que o ultrapassa (Didry, 2011).

Símbolo visível da solidariedade social, o direito é 'repressivo' nas formas de solidariedade 'mecânica' e 'restitutivo' nas formas de solidariedade 'orgânica'. Consequentemente, a justiça durkheimiana é uma justiça restitutiva, que restabelece o curso regular das coisas por meio de compensações às vítimas. 0 direito se apresenta, então, como referência ao dever-ser, e serve para fixar os objetivos visados pelos juízes que, a pedido dos indivíduos, buscam restabelecer os fatos anteriores na sua forma normal. Por isso, uma justiça responsável não deve perturbar o desenvolvimento das atividades sociais. A justiça durkheimiana visa à busca de 'regularidades' compreendidas ao mesmo tempo como continuidade das atividades sociais e ordenamento das atividades segundo as regras (Didry, 2011).

Quanto aos aspectos anômicos da sociedade industrial, existentes notadamente no que tange às relações entre o capital e o trabalho, uma mais forte regulamentação jurídica deve ser implementada para remediá-los. Tratando-se do contrato, o que Durkheim evidencia é a 'descoberta do social', que define como a liberdade individual, essencial para a realização do contrato, pois é o jogo das relações sociais que se faz sentir na ação contratual. Mas tudo não é contratual no contrato: os únicos compromissos contratuais são os que foram realizados pela livre vontade dos indivíduos. Inversamente, toda obrigação que não é mutuamente consentida não é contratual. Dessa forma, o contrato depende da regulamentação, que é obra da sociedade e não de particulares (Didry, 2011).

Também as noções durkeimianas do crime e da pena são importantes para a sociologia do direito. Na sua obra Les règles de la méthode sociologique, Durkheim (1895; 1947) afirma a funcionalidade social do crime, que sendo uma 'moralidade negativa', serve para reforçar os padrões gerais de socialização. A funcionalidade social do crime determina seu caráter de normalidade, e o crime é considerado um fenômeno patológico quando ultrapassa o limiar de tolerância da sociedade em que se manifesta. A pena é, então, o resultado da reação social, mas para que possa anular o mal causado pelo crime, precisa ser regular e eficaz. A função das sanções repressivas é de proteger e, por essa maneira, sustentar os valores da consciência coletiva (Giddens, 1978, p. 27). Assim, pode-se medir o bom funcionamento de uma sociedade pela maneira como esta trata e reprime o crime. $\mathrm{Na}$ sua teoria da evolução da pena, Durkheim mostrou que a severidade da pena não corresponde apenas 
ao tipo de reação social que o crime provoca. A pena pode ser também vinculada ao abuso do poder do Estado, notadamente quando não há contra-poderes. De fato, quando não há resistência organizada, a piedade perde seus direitos (Bouglé, 1935).

Quanto à sociologia do direito de Max Weber, que levou muito tempo para ser reconhecida na França em razão do domínio do paradigma holista, Jean Carbonnier afirma que teve uma dupla desvantagem: para os sociólogos não era suficientemente marxista, e para os juristas não era suficientemente clara (Grosclaude, 1986). Nesse país, o pensamento de Weber foi difundido por Raymond no livro Les étapes de la pensée sociologique de 1967. A obra weberiana influencia então autores muito diferentes, como, entre outros, o próprio Aron e Pierre Bourdieu. A sociologia do direito de Weber mostrou que "toda a reflexão crítica sobre o direito pressupõe uma discussão da racionalidade jurídica" (Coutu, 1995, p. 11), mas sua noção de racionalidade, complexa e ambígua, sem significação uniforme, levou a uma pluralidade de sentidos (Coutu, 1995). No direito, a associação dos termos 'racional' e 'formal' significa que o formalismo é uma das categorias principais do racionalismo jurídico (Coutu, 1995).

No capítulo "Sociologia do direito" de seu livro Économie et société (1921), Weber analisa, a partir de uma visão histórica, onde se vê a influência do marxismo, os processos da racionalização do direito. Através da elaboração de tipos ideais do direito - método pelo qual responde à exigência de coerência lógica, mas que não visa construir um modelo axiológico (Coutu, 1995, p. 23) -, Weber caracteriza a tensão existente entre o racional e o irracional, e a contradição entre as racionalidades formais e as racionalidades materiais do direito. O tipo de direito 'racional-formal' concilia a previsibilidade com critérios de decisão do próprio sistema jurídico, e o tipo 'racional-material', tipo calculável, responde às demandas dos sistemas exteriores, éticos, religiosos ou políticos. No direito 'racional-material', em que as decisões dos problemas jurídicos são influenciadas por regras utilitaristas ou regras de oportunidade, os critérios de decisão podem corresponder a ideologias políticas. É o que observamos hoje em dia como bem mostrou Ferreira (2012; 2014).
Max Weber mostrou a influência da formalização jurídica nas esferas econômicas e sociais, e não simplesmente o contrário. Sendo uma esfera altamente racionalizada da sociedade moderna, o direito tem afinidades com outro agente de racionalização que é a economia capitalista, e essas afinidades provocam uma 'dupla articulação' das duas esferas: se o direito e as instituições jurídicas respondem às exigências econômicas, eles geram igualmente efeitos econômicos (Fleury, 2009, p. 41 e ss.). Do ponto de vista das relações da sociologia do direito com a política, as problemáticas weberianas são sempre atuais: como considerar o poder como legítimo? Como a obediência torna-se um dever?

Contra o positivismo reinante, Weber apontou para a necessidade da sociologia do direito levar em conta as atividades de interpretação das regras e de adaptação às regras, bem como das antecipações que cada ator efetua em relação aos outros. Desse modo, a sociologia do direito compreensiva é muito relevante para os estudos empíricos do direito, pois incita os pesquisadores a perceber os efeitos das normas nas atividades concretas dos indivíduos, sem deixar de ter em conta o nível de conhecimento da norma de referência ideal, o que é indispensável à compreensão das atividades concretas que concernem determinadas normas (Lascoumes, 1995, p. 12).

Quanto à sociologia funcionalista, mesmo se Bourdieu a considerou como um imperialismo cientifico que desenvolveu, com Parsons, Merton e Lazarsfeld estratégias de dominação ideológica (Bourdieu, 1987 , p. 50), pode-se tirar alguns ensinamentos para a sociologia do direito, notadamente para a sociologia do desvio. Nesse campo, as teses de Parsons, inspiradas das noções durkheimianas de socialização e anomia, sustentam que a motivação à conformidade social e para o respeito das normas não é inata, mas resulta do aprendizado e da transmissão de valores e normas realizados pela socialização dos indivíduos. Portanto, se há falhas ou fracasso dos mecanismos de socialização, podemos estar diante de um 'desvio conjuntural' daqueles que não foram socializados, ou suficientemente socializados e motivados para adaptar-se às normas sociais. Esta ideia, quando transposta para o direito penal e sua violação, levanta uma questão essencial: pode a prisão ressocializar 
indivíduos que não foram anteriormente socializados ou que recusam a adoção das normas sociais e jurídicas em vigor em uma dada sociedade? Como disse em outro lugar, o discurso jurídico da ressocialização é uma falácia que somente justifica a funcionalidade social dos sistemas repressivos (Capeller, 1985).

Quanto à teoria de Robert Merton, que também se inspirou da noção durkheimiana de anomia, nos Tipos de Adaptação Individual (Merton, 1997, p. 172 e ss.), ele mostra que o desvio pode ser 'estrutural', e que o crime pode ser resultante da tensão que existe entre os objetivos propostos pela sociedade e a distribuição desigual dos meios dados aos indivíduos para poder atingi-los. Na visão durkeimiana, de fato, a anomia se caracteriza na sociedade moderna pela infinidade dos desejos, pela indeterminação dos objetivos, pela incerteza das esperanças legítimas (Duvignaud, 1973, p. 36 e ss.). A crítica neomarxista dos anos 1960-1970, acusou os funcionalistas de terem ignorado os conflitos sociais, e visto o direito como consensual, se manifestando no controle social, visto como positivo. Outras críticas vieram das teorias do interacionismo simbólico, notadamente da teoria do labelling approach de Howard Becker (1963) e da teoria da instituição total de Erving Goffman. Michel Foucault, na mesma época, publicou Surveiller et punir (1975), onde denunciou o poder disciplinar exercido nos espaços fechados e quadrilhados da prisão (Foucault, 1975; Giddens, 1987; pp. 201-217; Capeller, 2011, p. 64 e ss.).

\subsection{O direito presente nas teorias sociais atuais}

A sociologia do direito pode enriquecer-se também com os paradigmas comunicacionais, que indicam as lógicas dicotômicas do direito. Essas teorias, elaboradas nas últimas décadas do século $X X$, integram as problemáticas jurídicas como fios condutores para a compreensão das esferas sistêmicas que colonizam o 'mundo da vida' (Habermas, 1981). Para Luhmann, o direito é um subsistema autorreferencial, estratégico e funcional, que pode ser legitimado pelos procedimentos jurídicos (Luhmann, 2001). Para Habermas, o direito pode ser um 'direito instituição', que corresponde às lógicas do 'mundo da vida', e um direito 'médium', que corresponde às lógicas sistêmicas. 0 primeiro não pode ser legitimado apenas pelos proce- dimentos legais - como é o caso do direito constitucional ou do direito penal, cuja normatividade integra aspectos morais. Se a legitimidade das normas é questionada nas práticas da vida, um apelo à legalidade não é suficiente para legitimá-las (Habermas, 1981).

Outras teorias sociais contemporâneas são interessantes para a reflexão sócio-jurídica, notadamente a teoria da estruturação de Anthony Giddens e a teoria do reconhecimento social de Axel Honneth. A primeira fornece um sólido quadro conceitual para a pesquisa empírica na medida em que aponta para a maneira com que os atores sociais e as estruturas interagem na dualidade estrutural, incitando os atores sociais a mobilizarem cotidianamente as regras e os recursos normativos para co-constituir os sistemas sociais. Inspirando-me nessa teoria, pude observar, no final da década de 1990, numa pesquisa empírica sobre o impacto da normatividade do Sistema Schengen, como nas práticas rotineiras os atores locais do controle (situados na fronteira França-Espanha) adotavam uma atitude receptiva ou não receptiva em relação às normas e instituições transnacionais de controle, alguns agindo na rotina profissional 'com o direito', outros 'contra o direito', numa atitude de rejeição psicológica das normas transnacionais (Capeller, 1999).

Quanto à teoria do reconhecimento social, que examina o desenvolvimento histórico do direito no sentido dos direitos fundamentais liberais e do direito subjetivo (Honneth, 1992, p. 190 e ss.; Rosenfield \& Saavedra, 2013), ela procura saber como o indivíduo desenvolve a consciência de ser sujeito de direito, e como a autorrelação que caracteriza a forma de reconhecimento do direito se realiza na esfera do reconhecimento (Honneth, 1992, p. 177). Para Honneth, o direito é uma forma de expressão simbólica que, pelos seus potenciais de efetivação, permite aos indivíduos serem reconhecidos socialmente.

Igualmente muito relevante para a sociologia do direito é o debate sobre a redistribuição social e o reconhecimento social (Fraser \& Honneth, 2003). A redistribuição se refere às estruturas econômicas, às classes sociais, às instituições que regulam, nas sociedades contemporâneas, o trabalho, o acesso aos bens e serviços; o reconhecimento, velha categoria hegeliana retomada pelas teorias críticas e feministas, refere- 
-se à diferença dos indivíduos, aos seus direitos, às suas identidades. Em todo o lugar quando e onde emergem questões étnicas, multiculturais, sexuais e sociais, essas abordagens teóricas fornecem uma importante base reflexiva.

\section{Considerações finais}

Em termos não conclusivos, gostaria de dizer que nas sociedades da modernidade complexa e avançada onde vivemos, a sociologia do direito em movimento orienta-se para uma mestiçagem disciplinar, sem que isso signifique nem o banimento do direito dos estudos sociológicos nem a adoção a uma espécie de impressionismo jurídico. Retirar o direito dos limites do cientifismo positivista, examinar o discurso jurídico como fundamento de formas diversas de constituição e concretização social do direito, inspirar-se crítica e desconfiadamente das teorias sociais produzidas em outros contextos culturais, econômicos, políticos e sociais, enxergar suas próprias realidades com novos olhos, essas parecem ser as tarefas primordiais dos juristas que querem fazer pesquisa sócio-empírica. Por isso as perspectivas abertas pelas epistemologias do Sul (Santos, 2014) são importantes para os pesquisadores brasileiros.

111111111111111111111111111111111111 


\section{Referências}

Amselek, P. (1994). Théorie du droit et science, Paris: PUF.

Arnaud, AJ. (2014). La Gouvernance outil de participation. Paris: Lextenso.

Arnaud, AJ., \& Junqueira, E. B. (dir.) (2010). Dictionnaire de la Globalisation: Droit - Science politique - Sciences sociales. Paris: LGDJ-Lextenso Edit.

Arnaud, AJ. (2004). Entre modernité et mondialisation: Leçons d'histoire de la philosophie du droit et de l'État. Paris: LGDJ.

Arnaud, AJ., \& Fariñas Dulce, M. J. (1998). Introduction à l'analyse sociologique des systèmes juridiques. Bruxelles: Éd. Bruylant.

Arnaud, AJ., \& Guibentif, P. (1993). Niklas Luhmann, observateur du droit. Paris: LGDJ.

Arnaud, AJ. (2003). Critique de la raison juridique. Vol. 1 - Où va la sociologie du droit ? Paris, LJDG, 1981 Vol. 2 - Gouvernants sans frontières. Entre mondialisation et post-mondialisation. Paris, LGDJ-EJA.

Arnaud, AJ. (dir.) (1993). Dictionnaire Encyclopédique de Théorie et de Sociologie du Droit. Paris: LGDJ.

Arnaud, A. (1988). Droit et Société: un carrefour interdisciplinaire. Revue Interdisciplinaire d'études juridiques, (21), 7-32.

Atias, C. (1985). Épistémologie Juridique. Paris:PUF.

Bauman, Z. (2000). Modernidade líquida. Rio de Janeiro: Zahar.

Benoist, J., \& Jarsenti, B. (2001). Phénoménologie et sociologie. Paris: PUF.

Berthelot, JM. (2011). Epistémologie des sciences sociales. Paris: PUF.

Bougle, C. (1935). Bilan de la sociologie française contemporaine. Paris: Librairie Félix Alacan. Disponível em: <http://classiques.uqac.ca/classiques/ bougle_celestin/bilan_socio_franc_contemp/Bilan_socio_franc_contemp.rtf>.

Bourdieu, P. (1986). La force du droit. Eléments pour une sociologie du champ juridique. Actes de la recherche en sciences sociales, (64), 3-19.

Bourdieu, J., Champagne, P. \& Wacquant, L. (2013) Théorie du champ. Actes de la Recherche en Siences sociales, 200(spécial).

Capeller, W. (2011). Relire Giddens. Entre Sociologie et Politique. Paris: LJDG/Lextenso, 2011.

Capeller, W. (2003). Comment les sciences sociales se pensent-elles?. Revue Droit et Société, (53), 215-228.

Capeller, W. (1999) La constitution du système Shen- gen: son impact sur les acteurs locaux du contrôle. Revue Droit et Société, (42/43), 265-285.

Capeller, W. (1995). L'engrenage de la répression. Stratégies sécuritaires et politiques criminelles. Paris: LGDJ.

Capeller, W. (1992). Dossier Transformations de l'Etat et changements juridiques: l'exemple de l'Amérique latine. Revue Droit et Société, (22).

Capeller, W. (1985). O Direito pelo avesso: análise do conceito de ressocialização. Temas IMESC, Soc. Dir. Saúde, 2(2), 127-134.

Carbonnier, J. (1972). Sociologie juridique. Paris: PUF. Chazel, F. (2000). Emile Durkheim et l'élaboration d'un programme $d$ recherche en sociologie du droit. Aux fondements de la sociologie (pp. 169182). Paris: PUF.

Chazel, F. \& Commaille, J. (1991). Normes juridiques et régulation sociale: Retour à la sociologie générale. Normes juridiques et régulation sociale. Paris: LGDJ.

Chevalier, L. (1958). Classes laborieuses et classes dangereuses à Paris pendant la première moitié $d u$ XIXe siècle. Paris: Plon.

Commaille, J. (2014). Présentation du dossier Faire avec ou dé-faire le Droit en « fabriquant » du droit. Revue Droit et Société, (86), 9-10.

Commaille, J. (2014). Présentation du dossier La place du droit dans l'œuvre de Pierre Bourdieu. Revue Droit et Société, 1(56-57), 11-15.

Commaille, J., Dumoulin, L., \& Robert, C. (dir.). (2000). La juridicisation du politique: Leçons scientifiques. Paris: LGDJ-MSH.

Commaille, J. (1994). L'esprit sociologique des lois: essai de sociologie politique du droit. Paris :PUF.

Commaille, J., \& Perrin, JF. (1985). Le modèle de Janus de la sociologie du droit. Revue Droit et Société. (1), 95-110.

Comte, A. (2009). Catéchisme positiviste. Paris : Ed. Sandre.

Coutu, M. (1995). Max Weber et les rationalités du droit. 15. Paris/Québec: LGDJ/PULaval.

Delmas-Marty, M. (1986). Le flou du Droit. Paris: PUF.

Delmas-Marty, M. (1998). Trois défis pour un droit mondial. Paris: Le Seuil.

Didry, C. (2011). Durkheim et le droit, ouverture et limites d'une découverte sociologique. In C.H. Cuin, \& P. Duran. Le travail sociologique, du concept à l'analyse. Mélanges en honneur de François Chazel (pp. 49-61). Paris: Presses Universitaires de 
Paris -Sorbonne.

Dupré de Boulois, X., \& Kaluszynski, M. (2011), Le droit em révolution (s). Regards sur la critique du droit des années 1970 à nos jours. Collection Droit et Société. Recherches et Travaux. Paris : Lextenso.

Durkhein, E. (1947). Les règles de la méthode sociologique. Paris: PUF.

Duvignaud, J. (1973). L'anomie: Hérésie et subversion. Paris: Ed. Anthropos.

Fassó, G. (1974). Histoire de la philosophie du droit: XIX e et XXe siècles. Paris: LGDJ.

Ferreira, A. C. (2014). Política e sociedade: teoria social em tempo de austeridade. Porto: Vida Económica.

Ferreira, A. C. (2012). Sociedade da Austeridade e Direito do Trabalho de Exceção. Lisboa: Vida Económica.

Foucault, M. (1975). Surveiller et punir. Paris: Gallimard, 1975.

Fraser, N., \& Honneth, A. (2003). Redistribution or Recognition? A Political-Philosophical Exchange. Londres : Verso.

Giddens, A. (1987). La constitution de la société. Paris: PUF

Giddens, A (1978). As ideias de Durkheim. São Paulo: Cultrix.

Grosclaude, J. (1986) Introduction à Max Weber. Sociologie du droit. Paris: PUF.

Guerra Filho, W. S. (2008) Subsídios para uma crítica fenomenológica ao formalismo da ciência dogmático-jurídica. Cadernos da EMARF, Fenomenologia e Direito, 1(1), 1-100.

Guibentif, P. (2010). Foucault, Luhmann, Habermas, Bourdieu. Une génération repense le droit. Colletion Droit et Société, Paris: LJDG/Lextenso.

Habermas, J. (1987). Théorie de l'agir communicationnel, tome 2, Pour une critique de la raison fonctionnaliste. Paris: Fayard.

Kalinowski, G. (1969). Querelle de la science normative. Paris: LGDJ.

Kelsen, H. (1962). Théorie pure du droit. Paris: Dalloz.

Lasserre, V. (2013). Du progrès et de la promotion des savoirs. L'Université et l'enseignement du droit au XXI siècle. Revue de droit d'Assas, (8), 24-27.

Luhmann, N. (2004). Law as a Social System. Oxford: Oxford University Press.

Luhmann, N. (2001). La légitimation par la procedure. Les Presses de l'Université Laval: CERF.

Melkevik, B. (1992). Transformations du droit: le point de vue du modèle communicationnel. Les Cahiers de Droit, 33 (1), 115-139.

Merton, R. K. (1997). Eléments de théorie et de méthode sociologique. Paris: Armand Colin.

Ost, F., \& Van De Kerchove, M. (1988). Le système juridique entre ordre et désordre. Paris: PUF.

Queiroz, E. (1982). A tragédia da rua das flores. São Paulo: Letras.

Ricci, R. (2002). Le statut épistémologique des théories juridiques: essai de définition d'une pratique scientifique juridique. Revue Droit et Société, (50), 151-183.

Rosenfield, C. L., \& Saavedra, G. A. (2013). Reconhecimento, teoria crítica e sociedade: sobre desenvolvimento da obra de Axel Honneth e os desafios da sua aplicação no Brasil. Sociologias, 15(33), 14-54.

Saffon, M. P. \& Villegas, M. G. (2011). Critique du droit au Brésil, en Argentine et en Comombie. In D. de Boulois, \& M. Kaluszynski (org). Le droit en révolution(s). Regards sur la critique du droit des années 1970 à nos jours. Collection Droit et Société Recherches et Travaux. Paris: LGDJ, 149-172.

Santos, B. S. (2014). Epistemologies of the South: Justice against Epistemicide. Boulder: Paradigm Publishers.

Santos, B. S. (1986). Oração de Sapiênça, Um discurso sobre as Ciências. Coimbra.

Silveira, F. L. (2002). A Teoria do Conhecimento de Kant: o idealismo transcendental. Cadernos $\mathrm{Ca}$ tarinenses de Ensino de Física, 19(especial), 28-51. Disponível em: http://www.if.ufrgs.br/ lang/Textos/KANT.pdf.

Solinis, G. (ed.). (2005). Construire des gouvernances: entre citoyens, décideurs et scientifiques. Bruxelas: PIE - Peter Lang.

Wallerstein, I. (1980). Le Système du monde du XVe siècle à nos jours. Paris: Flammarion.

Weber, M. (1971, 1995, 2003). Economie et Société (Trad. F. de Julien Freund). Paris: Plon.

Weber, M. (1986). Sociologie du droit. Paris: PUF.

Wróblewski, J. (1983). 'Fuzziness' of Legal system. Essays in Legal Theory in Honor of Kaarle Makkonnen, 16, 319-322.

Data de submissão/Submission date: 01.11.2014

Data de aceitação para publicação/Acceptance date: 21.12.2014 